\title{
STINGS OF ANTS OF THE LEPTANILLINAE (HYMENOPTERA: FORMICIDAE) ${ }^{1}$
}

\author{
By Charles Kugler \\ Biology Department \\ Radford University \\ Radford, VA 24142
}

\section{INTRODUCTION}

Leptanilla is a rarely collected genus of tiny, subterranean ants that probably specialize on geophilomorph centipedes (Masuko 1990). Because queens are dichthadiiform as in army ants of the Ecitoninae and Dorylinae, the Leptanillinae (Leptanilla plus some male-based genera) have often been considered relatives of those subfamilies (taxonomic history in Wheeler and Wheeler 1965). Masuko (1990) has shown that Leptanilla japonica has some legionary behaviors. Now, however, the subfamily is not uniformly legionary after Bolton (1990a) added the new genera Anomalomyrma, Protanilla, and transferred in Apomyrma from the ponerine tribe Amblyoponini. With those additions, Bolton (1990a) initially proposed that leptanillines are the sister-group of the ponerines, but subsequent analysis made him revive the hypothesis that leptanillines are the sister-group of the doryline section (Bolton, 1990b).

In this paper I test these alternative hypotheses using a previously unexplored character system, the sting apparatus. The sting apparatus, pygidium and hypopygium were dissected from representatives of the three leptanilline tribes: Leptanillini (Leptanilla), Apomyrmini (Apomyrma) and Anomalomyrmini (Protanilla). Workers and queen of Leptanilla are compared. Phylogenetic

\footnotetext{
${ }^{1}$ This paper is dedicated to William L. Brown, Jr., to whom I owe a great debt of gratitude for serving as my thesis advisor and mentor. Working in his lab was a pleasure and always interesting. I deeply appreciate his support and encouragement throughout my career. Bill is a generous soul-always providing what he can without question, including room and board at Chez Brown when needed. $\mathrm{He}$ is also a good friend. I cherish memories of gourmet dinners with Bill and Doris, homemade pear cordial, Fats Waller, recording frogs in the New Jersey Pine Barrens, and dodging contrabandistas in the Guajira of Colombia. Thanks Bill, for everything. Manuscript received 14 July 1992
} 
relationships among the three genera are discussed and comparisons are made with the apparatuses of Nothomyrmeciinae, Myrmeciinae, Ecitoninae, Dorylinae, and primitive Ponerinae.

\section{Methods}

Sting apparatuses were dissected from the ants, cleared in hot lactophenol solution, and usually dissected further into two halves and a separate sting. The stings were mounted in glycerin jelly for ease of precise positioning and repositioning for different views. The other sclerites were usually mounted in Canada balsam. Occasionally whole apparatuses were mounted in glycerin jelly.

Voucher specimens identified with the label "C. Kugler 1992 Dissection voucher" are deposited in the Museum of Comparative Zoology, Harvard.

Preparations were drawn and measured using a Zeiss KF-2 phase contrast microscope with an ocular grid. Accuracy is estimated at $\pm 0.001 \mathrm{~mm}$ at $400 \times$ magnification. Drawings presented here are sometimes reconstructions made from sketches of several preparations.

Quantitative characters are enumerated for only one side of paired sclerites. Measurements of the sting regions are shown in Figure 2. StingL is normally the sum of the lengths of the sting regions. However, in Protanilla and Leptanilla, which have no valve chamber, the StingL was measured as the maximum straight line distance between the sting shaft apex and sting base, excluding the articular processes. The relative sizes of the stings are compared using several indices: StingL/Hind TibiaL, and whenever possible, the Index of Reduction (Sting ShaftL/PronotalW). The intervalvifer sensilla are a cluster of trichodea on the oblong plate just anterior to the articulation of triangular and oblong plates. The ramal sensilla are a row of trichodea inside the ramus of the oblong plate. The fulcral arm sensilla are clusters of campaniformia(?) along the ventral edge of the fulcral arm. The dorsoterminal chaeta of the gonostylus is a conspicuous chaeta located on the dorsal surface at the tip of the gonostylus in many ant genera. The companion seta is longer than other setae and located adjacent to the dorsoterminal chaeta. Other terms are identified in the figures and in Kugler (1978). 

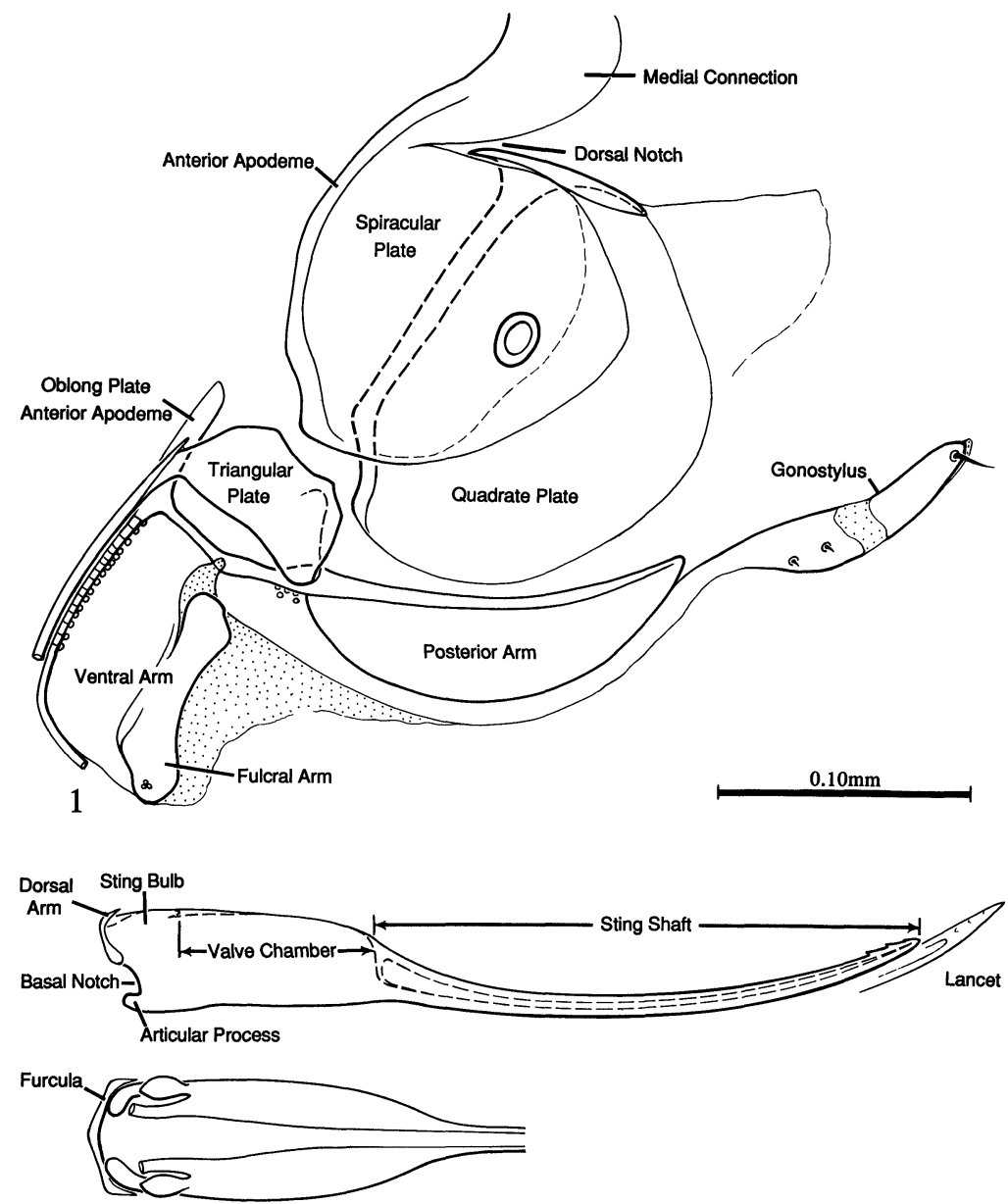

2

APOMYRMA

Figures 1-2. Sting apparatus of Apomyrma stygia workers. 1. Lateral views of spiracular, quadrate, oblong plates and gonostylus. Spiracular and quadrate plates have been moved dorsad to reveal underlying plates. 2. Above: lateral sting, furcula and end of lancet. Below: ventral furcula and anterior half of sting. All figures to same scale. 
Apomorphy and plesiomorphy of character states were based on outgroup comparison with the primitive ponerine Amblyopone pallipes (Kugler 1978).

\section{RESULTS}

Apomyrmini: Apomyrma

Specimens examined: A. stygia, 7 workers, Ivory Coast, Lamato, Toumodi, 1968, J. Lévieux. Determined by W. L. Brown, Jr.

Spiracular plate (Fig. 1). Anterior apodeme narrow. Medial connection completely sclerotized, widest medially. Spiracle not enlarged. Dorsal notch deep, narrow.

Quadrate plate (Fig. 1). Body larger than apodeme and overlapping much of the posterior arm of the oblong plate. Anterodorsal corner and lateral lobe moderately developed; medial lobe absent.

Anal plate. None visible in several good preparations. Area normally occupied by lateral and medial sclerites seems entirely membranous. No Sensilla.

Oblong plate (Fig. 1). Anterior apodeme long, narrow, weakly sclerotized. Posterior arm with narrow dorsal ridge and no subterminal tubercle. Ventral arm taller than long; fulcral arm linear. Postincision extends anterior to articulation of fulcral arm with posterior arm. Plate with 5 intervalvifer, 16-19 ramal, and 2-3 fulcral arm sensilla.

Gonostylus (Fig. 1). Slender; composed of 2 faintly visible, weakly sclerotized segments. Basal segment longer, with 1-2 short lateral chaetae; distal segment with $0-1$ longer lateral setae.

Triangular plate (Fig. 1). Dorsoapical and ventroapical processes short. No clear dorsal or medial tubercles. Attached to lancet ramus by a slender peduncle.

Lancet (Fig. 2). Long, curved, very slender; height uniform to apex. Apex acute, with 3 or 4 weak barbules. Basally with a pair of moderately large, subequal lancet valves.

Sting (Fig. 2). Long and slender. Sting shaft $69-71 \%$ of StingL (Index of Reduction 1.12), upcurved; apex acute, with 3 pair of dorsal barbules. Valve chamber 21-22\% of StingL, markedly higher and wider than base of sting shaft. Sting bulb short (about $8 \%$ of StingL), not externally differentiated from valve chamber. Basal ridge weak; no anterolateral processes. Articular processes small. StingL/Hind TibiaL 1.64-1.65 (N=2). 
Furcula (Fig. 2). Does not show up well in lateral view. Seems weakly sclerotized and appressed to sting base. Lateral arms very slender; dorsal arm short.

Pygidium. Narrow, broadly overlapping hypopygium laterally. No sign of pygidial glands or reservoirs; no sculpturing of anterior margin. Setae sparsely cover all but midline of posterior half; no spines or tubercles.

Hypopygium. Apex notched. No sign of a sternal gland. Midline without pilosity.

\section{Anomalomyrmini: Protanilla}

Specimen examined. Protanilla $s p$. (probably undescribed), 1 worker Seifa-Utaki, Okinawa Is., 29-III-1975, K. Onoyama. Determined by C. Baroni Urbani.

Spiracular plate (Fig. 3). Large, oval. Spiracle small, in center of bottom half. Heavy anterior edge and wide medial connection.

Quadrate plate (Fig. 4). Body expanded ventrad and broadly overlapping the posterior arm of the oblong plate. Apodeme much smaller than body. Anterodorsal corner short; lateral lobes small.

Anal plate. None seen. Perhaps lost in preparation.

Oblong plate (Fig. 5). Anterior apodeme very long, thin. Postincision extends to dorsal ridge. Posterior arm with wide dorsal ridge that fans out caudad and has a median tubercle about midlength. In Fig. 5 the posterior arm has been flattened so that the shape of the dorsal ridge is normally what one would see in a dorsal view. Postincision extends to dorsal ridge. Lower portion of ventral arm lost in preparation; no fulcral arm visible in remaining portion. Plate with 10 intervalvifer, 19 ramal, and unknown fulcral arm sensilla.

Gonostylus. Both lost in preparation.

Triangular plate (Fig. 6). Body long and thin, curved; a large lateral tubercle present. Dorsoapical process long, thin; ventroapical process thick.

Lancet (Fig. 6). Saber-like, highest midlength. No valves at all. Apex with 4 large barbs; two angled up, two angled down.

Sting (Fig. 7). Sting shaft wider than high, upcurved. Sting apex with 3 pair of dorsal barbs; the middle pair largest and fused medially. Valve chamber indistinguishable both externally and internally. Sting bulb markedly wider and higher than base of sting 


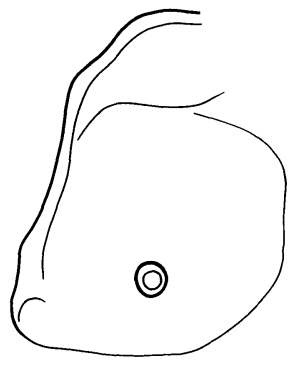

3
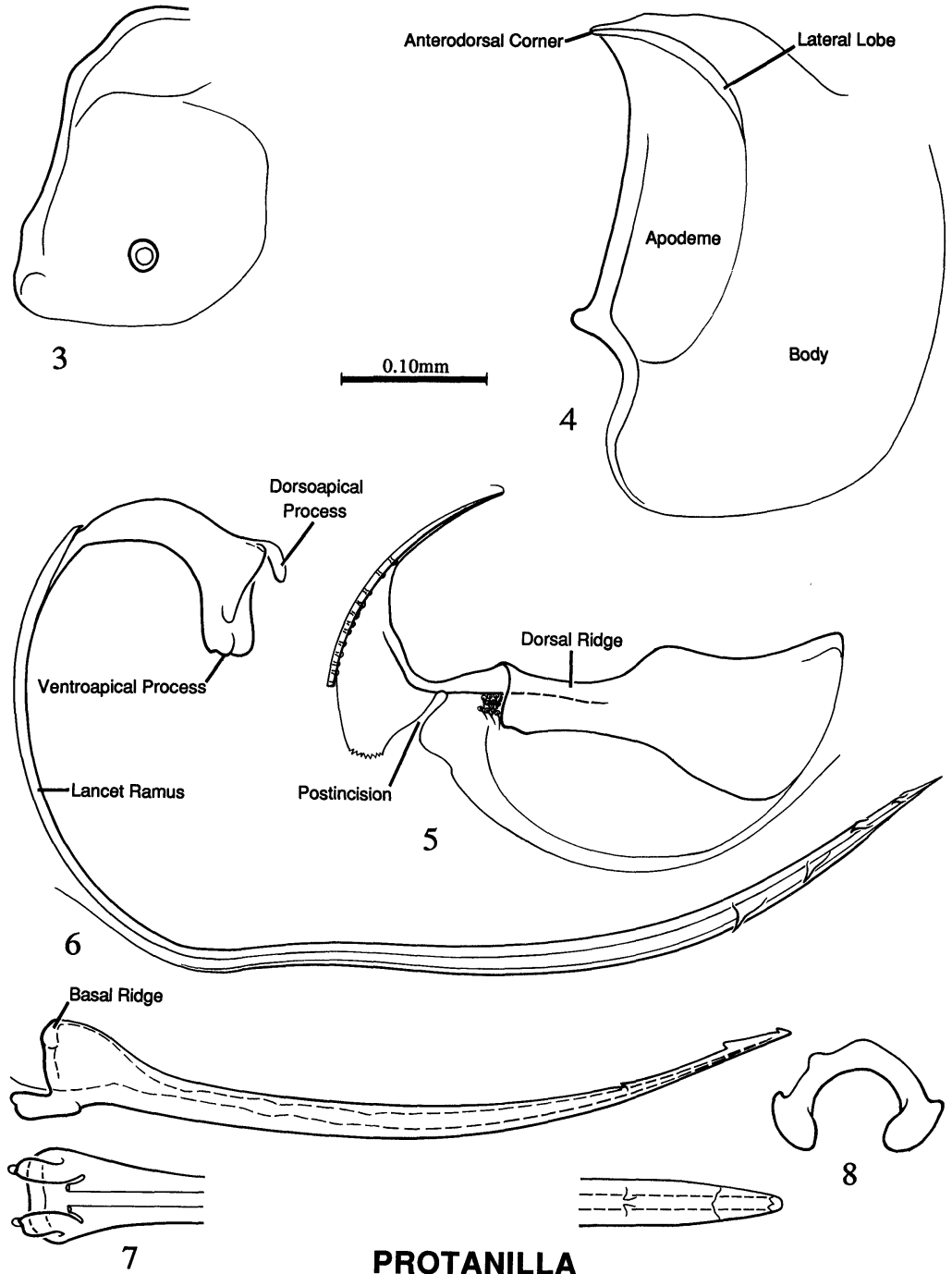

8

8

\section{PROTANILLA}

Figures 3-8. Sting apparatus of Protanilla sp. worker. 3. Lateral spiracular plate; dorsal view medial connection (part). 4. Lateral quadrate plate. 5. Lateral oblong plate, with dorsal view of dorsal ridge. Lower parts of ramus and ventral arm missing. 6. Lateral triangular plate and lancet. 7. Above: lateral sting. Below: ventral views of proximal and distal ends of sting. 8. Anterior view of furcula. All figures to same scale. 
shaft. Sting base with large basal ridge and articular processes. StingL/Hind TibiaL 1.11.

Furcula (Fig. 8). Thick, U-shaped, with tubercles on extremities. Dorsal arm reduced to a low tubercle; a small parasagittal tubercle also present.

Pygidium. No sign of glands, reservoirs or sculpturing on anterior margin. Setae sparsely cover all but midline of posterior half; no spines or tubercles.

Hypopygium. No sign of glands. Apex notched. Sparsely setose; midline without pilosity.

Leptanillini: Leptanilla

Specimens examined: L. revelierei, 3 workers, Sardegna (Sardinia): Dint. Silius, 6-IV-85, Francello and Leo. One queen, Sardegna: Dint. Domusnovas, 22-V-85, Francello and Leo. Determined by C. Baroni Urbani.

Workers

Spiracular plate (Fig. 9). Posterior portion of plate very weakly sclerotized, making its shape difficult to discern, but plate appears strongly reduced dorsad and without a posterodorsal corner. Medial connection seems membranous. Anterior apodeme narrow; not completely sclerotized across midline. Spiracle small, near anterior edge.

Quadrate plate (Fig. 9). Dorsal edge with prominent anterodorsal corner and narrow lateral lobes. Apodeme and body of plate indistinguishable. Posterior edge of plate ill defined. Medial connection is as long (axially) as dorsal ends of quadrate plates, and continuous with anal plates.

Anal plates (Fig. 9). A median and two lateral plates seem present, but all are weakly sclerotized and poorly defined. Lateral plates seem fused dorsally to quadrate plates. Median plate with 10 long marginal and submarginal setae.

Oblong plate (Fig. 11). Anterior apodeme short, acute. Dorsal ridge very wide, projecting medially as a shelf; no terminal tubercle or extension. Ventral arm short; fulcral arm narrow, linear. Postincision extends anterior to the fulcral arm, but does not turn dorsad to the dorsal ridge. Plate with 4-5 ramal, 2-3 intervalvifer and 0 fulcral arm sensilla. 

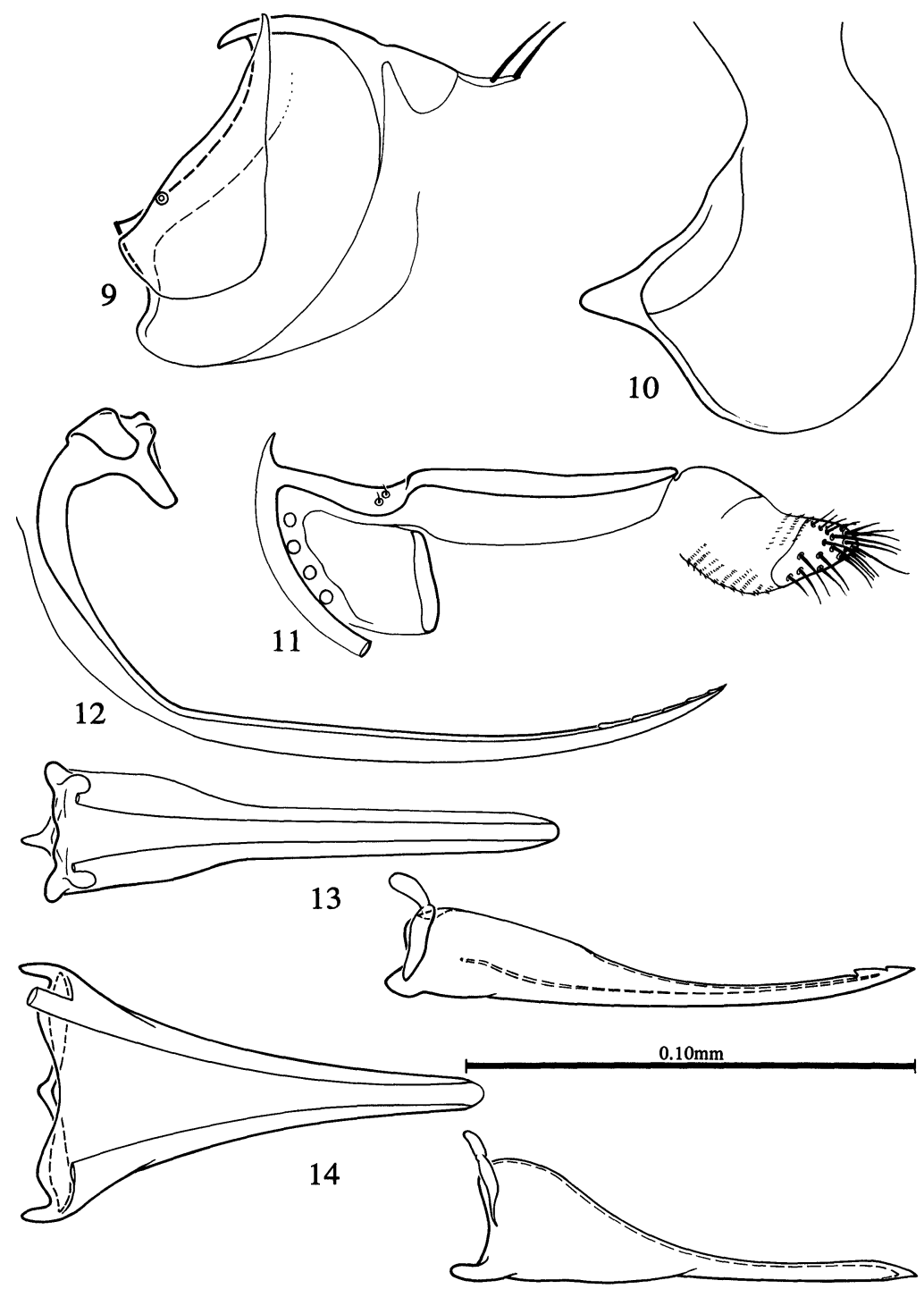

LEPTANILLA

Figures 9-14. Sting apparatus of Leptanilla revelierei. 9. Lateral spiracular, quadrate, and anal plates of worker. 10. Lateral quadrate plate of queen. 11. Lateral oblong plate and gonostylus of worker. 12. Lateral triangular plate and lancet of worker. 13. Ventral, lateral sting and furcula of worker. 14. Ventral, lateral sting and furcula of queen. All figures to same scale. 
Gonostylus (Fig. 11). Composed of two short, thick, indistinct segments. All sensilla in the distal segment; one terminal seta slightly longer than others; no dorsoterminal chaeta.

Triangular plate (Fig. 12). Body with large lateral tubercle. Ventroapical process long, slender. No visible medial or dorsal tubercles.

Lancet (Fig. 12). Apex acute, strong, with 6 distinct barbs along dorsal edge. No visible valves in any preparation.

Sting (Fig. 13). Sting shaft short, apex strong, acute, with two large, unpaired dorsal barbs. No distinct valve chamber; internal dorsal wall well separated from external wall. Sting base medially concave; basal notches weak; anterolateral processes absent; articular processes project somewhat laterad. StingL/Hind TibiaL 0.74-0.78 (N=3).

Furcula (Fig. 13). Y-shaped, closely pressed to sting base, but not fused. Dorsal arm long, without lateral wings. Ventral arms taper to narrow points.

Pygidium. No modification of anterior border and no sign of pygidial glands. Absence confirmed by histological study of Hölldobler et al (1989). Setae sparsely cover all but midline of posterior half; no spines or tubercles.

Hypopygium. Anterior edge with a thickened oval chamber containing a dense circular pore plate in the middle. This is the sternal gland (Hölldobler et al 1989). Apex notched, with a median strip of thin cuticle extending from it about $2 / 3$ length of the sclerite. Midline without pilosity.

\section{Queen}

Spiracular plate. Like that of worker (Fig. 9) in the following ways: 1) tapered dorsad, 2) no posterodorsal corner or dorsal notch, 3) medial connection membranous and 4) spiracle closest to anterior edge. Differing form worker in having a prominent posteroventral corner and wider medial connection. Each plate seems to have 3-4 campaniform(?) sensilla and one plate has a large seta in its center.

Quadrate plate (Fig. 10). Medial connection broadly fused with anal plate as in worker, but shape of plate differs. Apodeme much smaller than body of plate; no medial or lateral lobes.

Anal plate. Semicircular, wider than long, larger than quadrate plate. Lateral extremities broadly confluent with the dorsal ends of 
the quadrate plates. Plate with 21 long, marginal and submarginal setae.

Oblong plate. Posterior arm as in worker (Fig. 11); the rest lost in preparation. Plate with 2 intervalvifer sensilla; others unknown.

Gonostylus. Shape as in worker (Fig. 11), but with no hint of two segments. Distal two thirds with about 32 setae and 1 basiconic sensillum. One terminal seta is larger than the rest; no dorsoterminal chaeta.

Triangular plate. Lower body broken off, but the rest is like that of worker (Fig. 11).

Lancet. Like that of worker (Fig. 12), but barbs vestigial.

Sting (Fig. 14). Relatively shorter than that of worker (StingL/ Hind TibiaL 0.50). Sting shaft apex acute, but lacks barbs. Valve chamber region not detectable; no internal dorsal wall seen at all. Sting base markedly higher and wider than in worker, but otherwise similar. Articular processes distinct, more slender and not projecting laterad as in worker.

Furcula (Fig. 14). As in worker.

Pygidium and hypopygium. Unknown. Hölldobler et al (1989) found no sternal gland, nor did they report a pygidial gland.

\section{DisCUSSION}

Comparison of castes in Leptanilla

The few previous comparisons of worker and queen sting anatomy in ants have revealed no more than the usual individual differences in sclerite size or numbers of sensilla. In Leptanilla we see striking differences between workers and queen in shapes of the sting, spiracular and quadrate plates, and in segmentation of the gonostyli. The dichthadiiform queen also differs from the worker in glandular anatomy (Hölldobler et al 1989).

Comparisons of leptanilline genera

Apomyrma, Protanilla, and Leptanilla share the following apomorphic traits: 1) Quadrate plate with no discernable medial lobe and lateral lobe small. 2) Gonostyli short, with weak segmentation, 3) Furcular dorsal arm short, without lateral wings. These shared characters are consistent with the hypothesis of monophyly of the three genera, but not conclusively so. Since each commonly occurs with reduction of stinging function of the apparatus, the 
synapomorphies could have resulted from convergence, rather than common ancestry.

While the Protanilla and Apomyrma sting apparatuses look most similar, the similarities are mostly plesiomorphies also seen in Amblyopone and other ponerines. They may share a single apomorphic character (anal plates absent), but it is possible that Protanilla's anal plates were lost in preparation.

Leptanilla shares one apomorphic character with Apomyrma (furcula appressed to sting base) that often occurs convergently in ants with reduced stinging ability. It is unusual that Apomyrma has an appressed furcula when the rest of the sting is so well developed.

Leptanilla shares two apomorphic characters with Protanilla: 1) Triangular plate with a lateral tubercle, and 2) lancet valves absent (with corresponding loss of the sting's valve chamber). Moreover, these two genera have retained rather large barbs on the sting and lancets though the usual venom pumping mechanism has been lost. In contrast, Apomyrma has smaller barbs even though it has a large pumping mechanism. Leptanilla does sting its prey (Masuko 1990), evidently injecting venom by compression of the poison gland, rather than by shuttling of the lancets. Hölldobler et al (1989) report that Leptanilla has a "... a massively musculated poison gland [that] has not been found in other ant species." The anatomical similarities between Leptanilla and Protanilla are unusual and not likely to be convergent. Thus, it seems likely that Leptanilla and Protanilla had a common ancestor not shared by Apomyrma.

If that is true, Leptanilla's sting apparatus has changed substantially since its split with Protanilla. Leptanilla autapomorphies are: 1) Spiracular plates reduced dorsad. 2) Spiracle very close to anterior edge of spiracular plate. 3) Quadrate plates joined along their entire dorsal margins. 4) Oblong plate anterior apodeme very short. 6) Oblong plate postincision not extending to dorsal ridge. 7) Sting much shorter relative to size of the ant.

Comparisons with other ant genera

Apomyrma was originally placed with some hesitation in the ponerine tribe Amblyoponini because of similarities in diet and external anatomy (Brown et al 1971). Mystrium, another amblyoponine, has an apparatus very much like Amblyopone's (Kugler 
unpublished; Kugler 1978), but Apomyrma's apparatus is quite different. It lacks the large anal plate, has a much reduced furcula, and has different shapes of sting and oblong plates. Instead, the sting shape of Apomyrma is more similar to that of Nothomyrmecia, Myrmecia (Kugler 1980) and ponerines such as Paraponera (Kugler 1992; Hermann and Blum 1966). Thus, this study supports Bolton's (1990a) removal of Apomyrma from the Amblyoponini.

Leptanilla has often been placed near other legionary ants in various phylogenies and classifications, though with obvious uncertainty. Most recently, Bolton (1990a,b) challenged that view, but then reversed himself after further study. My examination of the stings of Dorylus and four genera of Ecitoninae (in prep.) reveals that the apparatuses of the Dorylinae and Ecitoninae are much more derived than those of the Leptanillinae. Moreover, each army ant subfamily has apomorphies not found in the three leptanillines discussed here (See also Hermann and Blum 1967 and Hermann 1969). So far the sting apparatus provides no support for considering the Leptanillinae a sister-group of Ecitoninae or Dorylinae.

My analysis does not question Bolton's (1990a) placement of Apomyrma in the Leptanillinae or his hypothesis that Ponerinae and Leptanillinae are sister-groups. But the analysis also does not provide support for those conclusions because knowledge of the ponerine sting apparatus is still too incomplete.

\section{SUMMARY}

Comparisons of the sting apparatus of three genera, representing three tribes within the subfamily Leptanillinae is consistent with Bolton's (1990a) proposed monophyly of this subfamily. Results also suggest that Protanilla (Anomalomyrmini) and Leptanilla (Leptanillini) are more closely related to each other than to Apomyrma (Apomyrmini). The apparatus of Leptanilla is most derived and is unusual in its strong dimorphism between queen and worker castes. The study fails to support the hypothesis of a close relationship with the Dorylinae and Ecitoninae. 


\section{ACKNOWLEDGEMENTS}

I thank W. L. Brown and C. Baroni Urbani for supporting this research with specimens, determinations and encouragement.

\section{Literature Cited}

BOLTON, B.

1990a. The higher classification of the ant subfamily Leptanillinae (Hymenoptera: Formicidae). Syst. Entomol. 15: 267-282.

1990b. Army ants reassessed: the phylogeny and classification of the doryline section (Hymenoptera, Formicidae). J. Nat. Hist. 24: 1339-1364.

Brown, W. L. JR., W. H. GotwALD, AND J. LÉVIEUX

1971. A new genus of ponerine ants from West Africa (Hymenoptera: Formicidae) with ecological notes. Psyche 77(1970): 259-275.

HermanN, H. R.

1969. The hymenopterous poison apparatus: Evolutionary trends in three closely related subfamilies of ants (Hymenoptera: Formicidae). J. Georgia Entomol. Soc. 4: 132-141.

HermanN, H. R. JR. AND M. S. Blum

1966. The morphology and histology of the hymenopterous poison apparatus. I. Paraponera clavata (Formicidae). Ann. Entomol. Soc. Amer. 59: 297-409.

1967. The morphology and histology of the hymenopterous poison apparatus. III. Eciton hamatum (Formicidae). Ann. Entomol. Soc. Amer. 60: 1283-1291.

Hölldobler, B., J. M. Palmer, K. Masuko, and W. L. Brown, JR.

1989. New exocrine glands in the legionary ants of the genus Leptanilla (Hymenoptera, Formicidae, Leptanillinae). Zoomorphology 108: 255-261.

KUGLER, C.

1978. A comparative study of the myrmicine sting apparatus. Stud. Entomol. 20: $413-548$.

1980. The sting apparatus in the primitive ants Nothomyrmecia and Myrmecia. J. Aust. Entomol. Soc. 19: 263-267.

1992. Stings of ants of the tribe Ectatommini (Formicidae: Ponerinae). Insecta Mundi 5: 153-166.

Masuko, $\mathrm{K}$.

1990. Behavior and ecology of the enigmatic ant Leptanilla japonica Baroni Urbani (Hymenoptera: Formicidae: Leptanillinae). Insectes Soc. 37: $31-57$.

WHEELER, G. C. AND J. WHEELER

1965. The ant larvae of the subfamily Leptanillinae (Hymenoptera, Formicidae). Psyche 72: 24-34. 

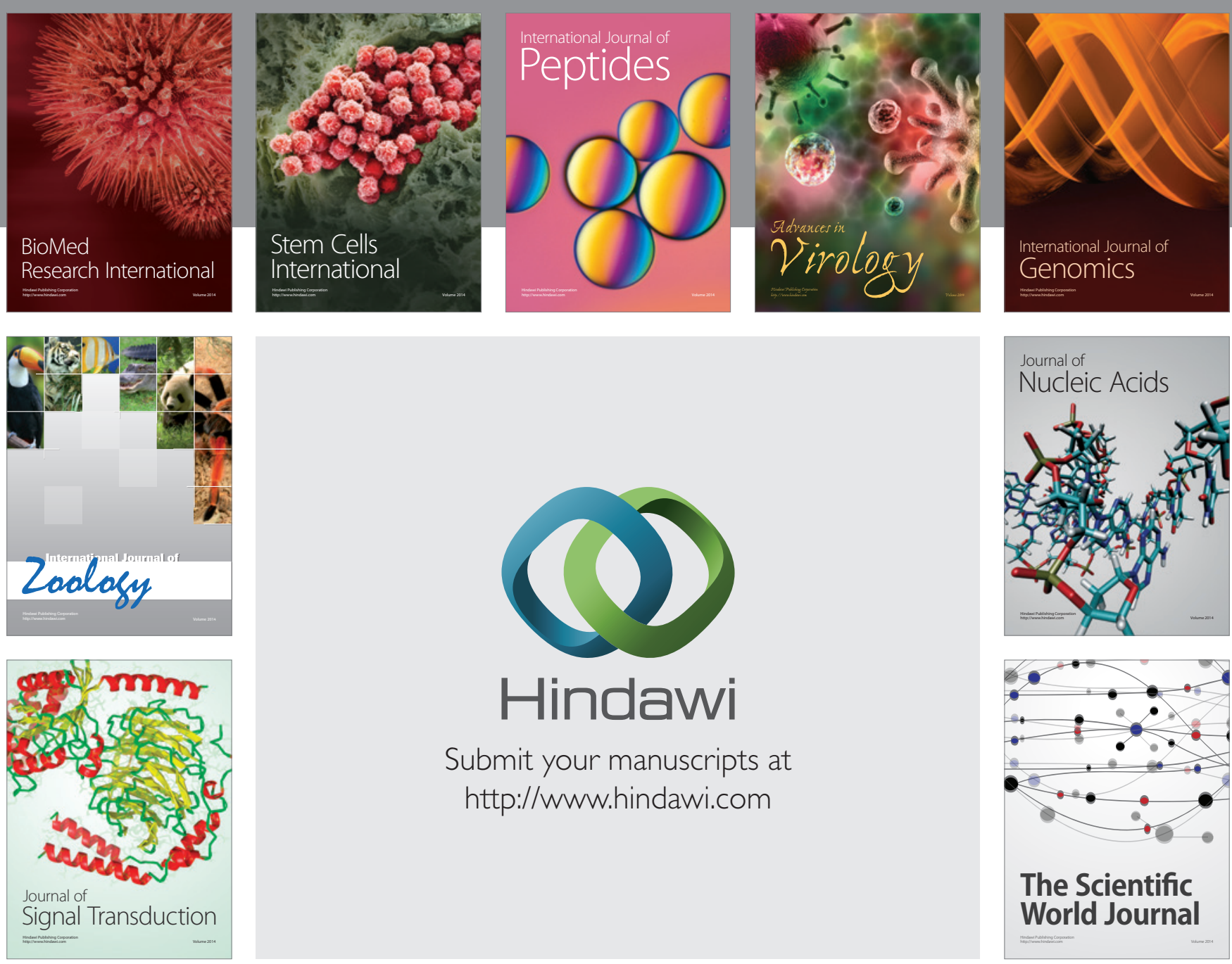

Submit your manuscripts at

http://www.hindawi.com
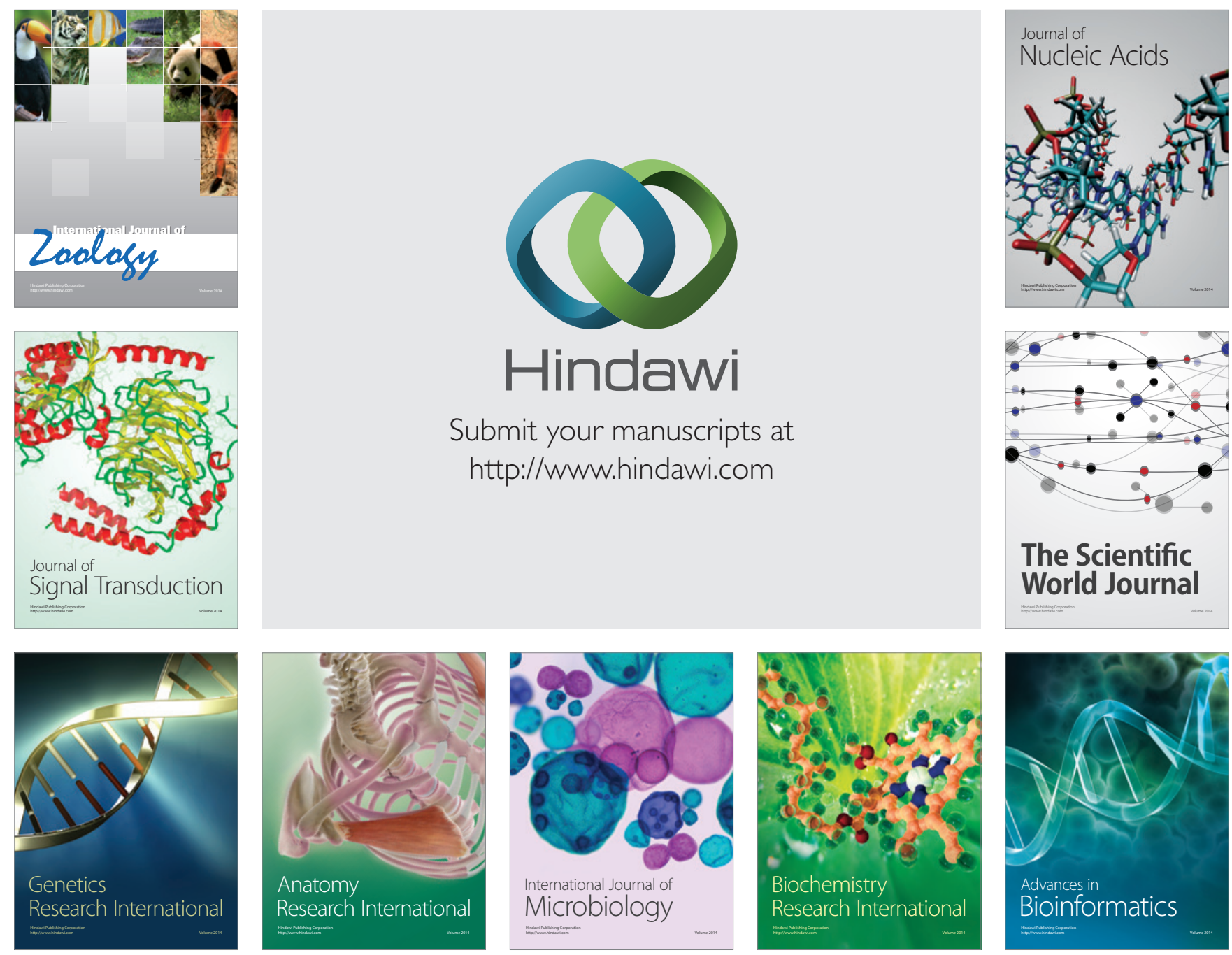

The Scientific World Journal
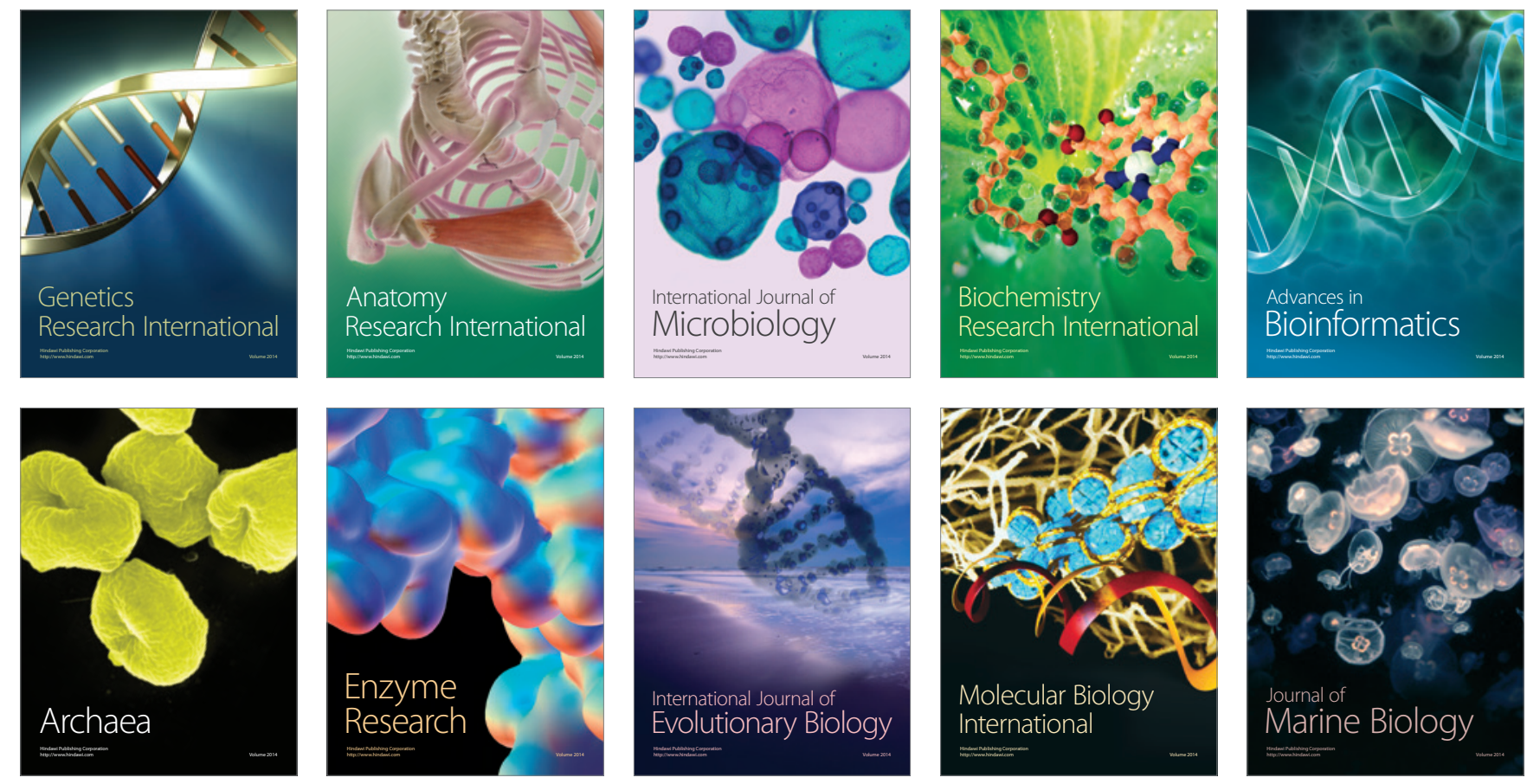